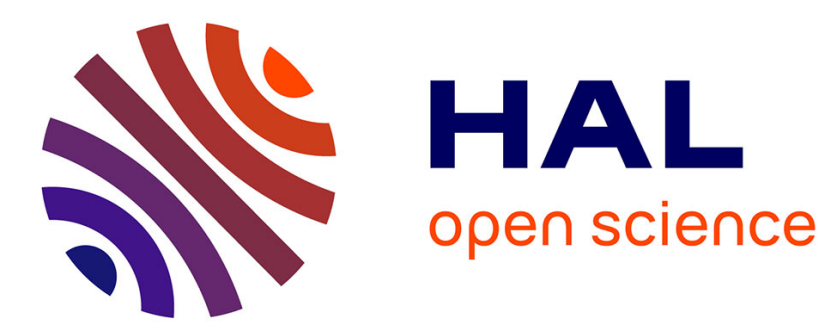

\title{
Corrosion protection of carbon steel by an epoxy resin containing organically modified clay
}

\author{
To Thi Xuan Hang, Trinh Anh Truc, Truong Hoai Nam, Vu Ke Oanh, \\ Jean-Baptiste Jorcin, Nadine Pébère
}

\section{- To cite this version:}

To Thi Xuan Hang, Trinh Anh Truc, Truong Hoai Nam, Vu Ke Oanh, Jean-Baptiste Jorcin, et al.. Corrosion protection of carbon steel by an epoxy resin containing organically modified clay. Surface and Coatings Technology, 2007, vol. 201, pp. 7408-7415. 10.1016/j.surfcoat.2007.02.009 . hal00806011

\section{HAL Id: hal-00806011 \\ https://hal.science/hal-00806011}

Submitted on 29 Mar 2013

HAL is a multi-disciplinary open access archive for the deposit and dissemination of scientific research documents, whether they are published or not. The documents may come from teaching and research institutions in France or abroad, or from public or private research centers.
L'archive ouverte pluridisciplinaire HAL, est destinée au dépôt et à la diffusion de documents scientifiques de niveau recherche, publiés ou non, émanant des établissements d'enseignement et de recherche français ou étrangers, des laboratoires publics ou privés. 


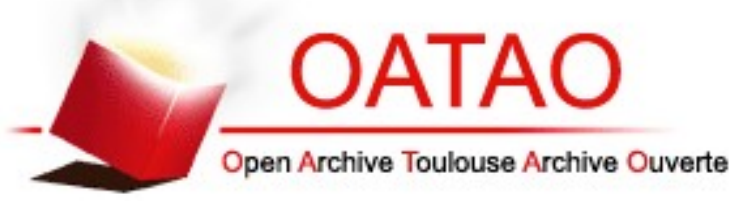

\section{Open Archive Toulouse Archive Ouverte (OATAO)}

OATAO is an open access repository that collects the work of Toulouse researchers and makes it freely available over the web where possible.

This is an author-deposited version published in: http://oatao.univ-toulouse.fr/

Eprints ID : 2420

To link to this article :

URL : http://dx.doi.org/10.1016/j.surfcoat.2007.02.009

To cite this version : Hang, To Thi Xuan and Truc, Trinh Anh and Nam, Truong Hoai and Oanh, Vu Ke and Jorcin, Jean-Baptiste and Pébère, Nadine ( 2007)

Corrosion protection of carbon steel by an epoxy resin containing organically modified clay. Surface and Coatings Technology, vol. 201 (nº 16 - 17). pp. 74087415. ISSN 0257-8972

Any correspondence concerning this service should be sent to the repository administrator:staff-oatao@inp-toulouse.fr 


\title{
Corrosion protection of carbon steel by an epoxy resin containing organically modified clay
}

\author{
To Thi Xuan Hang ${ }^{a}$, Trinh Anh Truc ${ }^{a}$, Truong Hoai Nam ${ }^{a}$, Vu Ke Oanh ${ }^{a}$, \\ Jean-Baptiste Jorcin ${ }^{\mathrm{b}}$, Nadine Pébère ${ }^{\mathrm{b}, *}$ \\ ${ }^{a}$ Laboratory for Protective Coatings, Institute for Tropical Technology, 18 Hoang Quoc Viet, Hanoi, Vietnam \\ ${ }^{\mathrm{b}}$ Centre Interuniversitaire de Recherche et d'Ingénierie des Matériaux (CIRIMAT) UMR CNRS 5085, ENSIACET, 118, \\ Route de Narbonne 31077 Toulouse Cedex 04, France
}

\begin{abstract}
This study focusses on the use of montmorillonite clay (MMT) treated with an organic compound (aminotrimethylphosphonic acid (ATMP)) and dispersed in an epoxy resin to improve corrosion protection of carbon steel. X-ray diffraction was performed to verify that the individual silicate layers were separated and dispersed in the epoxy resin. Corrosion resistance of the coated steel was evaluated by electrochemical impedance spectroscopy (EIS) and local electrochemical impedance spectroscopy (LEIS). Three systems were tested: the epoxy clear-coat, the epoxy resin containing $2 \mathrm{wt} . \%$ clay and the epoxy resin containing $2 \mathrm{wt}$ \% clay modified by ATMP (ATMP-modified clay). From conventional EIS, it was shown that the incorporation of clay or ATMP-modified clay in the epoxy matrix significantly improved the barrier properties of the coating. The corrosion resistance of the carbon steel coated by the epoxy resin containing ATMP-modified clay was higher than that obtained for the system containing non-treated clay. Local electrochemical measurements performed on scratched samples revealed the inhibitive role of ATMP at the carbon steel/coating interface.
\end{abstract}

Keywords: Epoxy resin; Clay; Aminotrimethylphosphonic acid; Corrosion protection; EIS; LEIS

\section{Introduction}

Organic coatings are widely used to prevent corrosion of metallic structures because they are easy to apply at a reasonable cost. It is generally accepted that the coating efficiency is dependent on the intrinsic properties of the organic film (barrier properties), on the substrate/coating interface in terms of adherence, on the inhibitive or sacrificial pigments used and on the degree of environment aggressiveness. Due to the problems of high toxicity associated with inhibitive pigments such as strontium or zinc chromates, various studies have been carried out to develop environmentally more acceptable coatings.

During the last years, polymer clay nanocomposites have attracted a lot of attention. It has been reported that the incorporation of a small amount (1-5\%) of layered clay in organic polymers leads to significant improvements in mechan-

\footnotetext{
* Corresponding author. Tel.: +335628856 65; fax: +33562885663.

E-mail address: nadine.pebere@ensiacet.fr (N. Pébère).
}

ical performance, thermal stability, and barrier properties of organic coatings [1-27]. These improvements are related to the morphology of the layered silicates and to the specific incorporation of the nanoparticules in the polymer. An ideal exfoliated morphology consists of a complete separation and dispersion of the individual silicate layers in a continuous polymer matrix. In this case, there is no longer any interaction between the layers, which are completely dissociated. In an exfoliated morphology, the spacing between the layers is larger than $100 \AA$, since the original spacing of the layered silicate is in the order of $10-30 \AA$ and there will be a large amount of polymer penetrating inside the interplanar gallery [17]. The most widely used layered silicate is montmorillonite (MMT). The chemical structures of MMT consist of two sheets of tetrahedral silica fused to an edge-shared octahedral-based sheet of either magnesium or aluminium hydroxide [18]. Generally, the surface of the clay needs to be modified to improve its dispersibility in the polymeric network. To render the layered silicate organophilic, the $\mathrm{Na}^{+}$and/or $\mathrm{Ca}^{2+}$ ions in the interlayer 
regions can be replaced by organic cations through a cation exchange reaction.

Numerous publications have been devoted to the preparation and characterization of the properties of organic modified clays but only few papers have presented results concerning the corrosion protection of metals. The improvement of the corrosion resistance of aluminium alloys [17] and of cold rolled steel [23-27] with polymeric films reinforced with organically modified clay has been clearly demonstrated. The corrosion protection was essentially related to the enhancement of the barrier properties of the coating. It is noteworthy that, as already mentioned, the clay is organically treated to favour its dispersibility in the polymeric matrix but to our knowledge, the choice of the organic compounds was not justified in relation with their inhibitive properties.

In the present study, montmorillonite clay was modified by aminotrimethylphosphonic acid (ATMP) and incorporated into an epoxy matrix. ATMP contains both an alkyl ammonium cation and three phosphonic groups. It was chosen because in previous studies [28,29], it was found that ATMP, tested in a sodium chloride solution as a corrosion inhibitor, limited the corrosion of carbon steel. The inhibitive action is a consequence of the anodic effect of the compounds due to the chelation of $\mathrm{Fe}^{2+}$ by the ATMP molecules [28,29]. The modified clay was characterized by infrared spectroscopy. X-ray diffraction was performed to verify the exfoliation of the silicate layers in the epoxy resin. The protective properties of epoxy coatings were evaluated by conventional electrochemical impedance spectroscopy (EIS). Local electrochemical impedance spectroscopy (LEIS) was used to investigate delamination phenomena at the steel/epoxy coating interface. Recently, it was shown that with LEIS it was possible to observe the initiation and propagation of delamination from an artificial defect at a steel/epoxy-vinyl primer interface [30]. Scanning electron microscopy and energy dispersive spectroscopy (SEM/EDS) were carried out to detect the presence of clay at the steel/epoxy coating interface.

\section{Experimental}

\subsection{Materials}

Carbon steel sheets $(150 \times 10 \times 2 \mathrm{~mm})$ were used as substrates. They were polished with an abrasive paper from 80 to 600 grades and degreased with xylene. The sample had the following composition in percent weight: $\mathrm{C}=0.35, \mathrm{Mn}=0.65$, $\mathrm{Si}=0.25, \mathrm{P}=0.035$ and $\mathrm{Fe}$ to 100 .

Aminotrimethylphosphonic acid (ATMP) was kindly supplied by Henkel Technologies-Concorde Chimie, France. The montmorillonite (MMT) was from Tuy Phong-Binh Thuan province in Vietnam. This clay consisted of a 2/1 ratio of silica to alumina, the swelling degree was $500 \%$ and the ion exchange capacity was $100-115 \mathrm{meq} / 100 \mathrm{~g}$. Before use, the hydrophilic clay was rinsed with pure water and a homogeneous suspension obtained.

\subsection{ATMP modification of the clay}

The pristine clay $(3.0 \mathrm{~g})$ was dispersed in distilled water $(300 \mathrm{ml})$ containing concentrated hydrochloric acid $(0.5 \mathrm{ml})$ and
ATMP (7.0 g). Then, the suspension was stirred at $70{ }^{\circ} \mathrm{C}$ for $24 \mathrm{~h}$ to afford a white precipitate. This precipitate was filtered and washed with water until no chloride was detected in the filtrate using a $0.1 \mathrm{M} \mathrm{AgNO}_{3}$ solution. The ATMP-modified clay was then dried at $80{ }^{\circ} \mathrm{C}$ in a vacuum oven for 2 days.

\subsection{Coating}

Epoxy resin was an Epikote 828 and the curing agent was dimethylaminopropylamine. Both compounds were purchased from Ciba Co. The ATMP-modified clay was incorporated in the epoxy coating at three concentrations: $2 \mathrm{wt} . \%, 3.5 \mathrm{wt} . \%$ and 5 wt. $\%$. Only the results obtained with $2 \%$ are reported here because with this concentration the best corrosion protection was obtained. This result validates the fact that a low clay content is sufficient to achieve the required properties.

The liquid paints were applied by air spraying and after drying (ambient temperature for $24 \mathrm{~h}$ ), the coatings were $30 \pm$ $3 \mu \mathrm{m}$ thick (measured by Minitest 600 Erichen digital meter).

\subsection{Analytical characterizations}

Fourier transform infrared spectra were recorded with a Nexus 670 Nicolet spectrometer over the range $4000 \mathrm{~cm}^{-1}-$ $400 \mathrm{~cm}^{-1}$. The spectra of pristine clay and ATMP-modified clay were recorded from a $\mathrm{KBr}$ disc. The spectrum of ATMP was obtained from smears on $\mathrm{KBr}$ plates. XRD patterns were recorded on a Siemens D5000 diffractometer with $\mathrm{Cu} \mathrm{K}_{\alpha} \mathrm{X}$-ray diffraction.

SEM-EDS analyses were carried out with a Leo 435 VP scanning electron microscope.

\subsection{Electrochemical characterizations}

For the classical EIS measurements, a three-electrode cell was used: the working electrode with an exposed area of $28 \mathrm{~cm}^{2}$, the saturated calomel reference electrode (SCE) and a platinum auxiliary electrode.

The global impedance measurements were performed using an Autolab PGstat30 over a frequency range of $100 \mathrm{kHz}$ to a few $\mathrm{mHz}$ with seven points per decade using $30 \mathrm{mV}$ peak-topeak sinusoidal voltage. For each system, three samples were tested to ensure reproducibility. Localized Electrochemical Impedance spectroscopy (LEIS) was carried out with a Solartron 1275. This method used a five-electrode configuration $[30,31]$. To observe delamination, an artificial defect was made manually with a cutting knife on the coated samples. For local electrochemical impedance mapping (LEIM), the probe was stepped across a designated area $(32,000 \times 24,000 \mu \mathrm{m})$ of the sample. The step size was $500 \mu \mathrm{m}$ in $X$ and $Y$ directions. Admittance was plotted rather than impedance to improve the visualization of the mapping. The maps were obtained at a fixed frequency of $5 \mathrm{kHz}$.

The corrosive medium was a $\mathrm{NaCl}$ solution (reagent grade) in contact with air, quiescent and at ambient temperature. The concentration for the conventional impedance measurements was $0.5 \mathrm{M}$ and $0.001 \mathrm{M}$ for the local impedance: local 


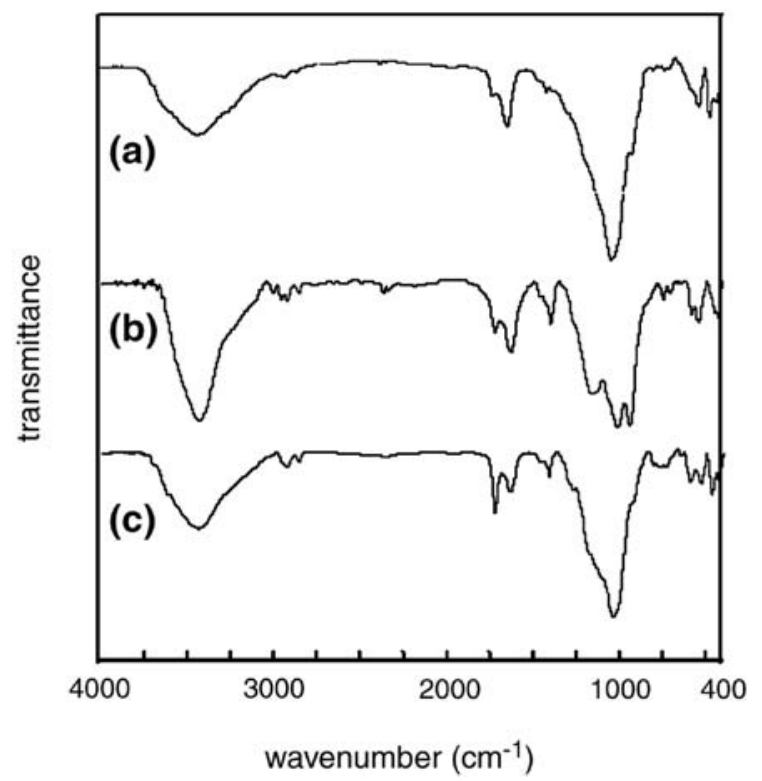

Fig. 1. FTIR spectra of (a) clay (MMT), (b) ATMP and (c) ATMP-modified clay.

measurements required low conductivity $\left(9.410^{5} \mathrm{~S} \mathrm{~cm}^{-1}\right)$ to optimize resolution.

\section{Results and discussion}

First, IR spectroscopy and X-ray diffraction analysis are presented to discuss the chemical modifications of ATMPmodified clay and the structural variations of the layered silicate after being dispersed in the epoxy resin. Then, global and local impedance data were analyzed to characterize the corrosion protection of the carbon steel coated by the epoxy resin containing ATMP-modified clay. Finally, SEM-EDS analysis was performed at the carbon steel/epoxy coating interface to have a better knowledge of the mode of action of the ATMPmodified clay at the carbon steel/epoxy coating interface.

\subsection{Characterization of ATMP-modified clay}

Fig. 1 presents the FTIR spectra of clay, ATMP and ATMPmodified clay. The characteristic bands of the spectra are given in Table 1. The spectrum of the clay shows bands at $1032 \mathrm{~cm}^{-1}$, $524 \mathrm{~cm}^{-1}$ and $468 \mathrm{~cm}^{-1}$ characteristic of the $\mathrm{Si}-\mathrm{O}, \mathrm{Al}-\mathrm{O}$ and $\mathrm{Mg}-\mathrm{O}$ bonds, respectively [32]. These bands were also found in

Table 1

Characteristic bands of FTIR spectra obtained for ATMP, clay and ATMPmodified clay

\begin{tabular}{llcl}
\hline $\begin{array}{l}\text { ATMP } \\
\left(\mathrm{cm}^{-1}\right)\end{array}$ & $\begin{array}{l}\text { Clay } \\
\left(\mathrm{cm}^{-1}\right)\end{array}$ & $\begin{array}{l}\text { ATMP-modified } \\
\text { clay }\left(\mathrm{cm}^{-1}\right)\end{array}$ & Bond \\
\hline- & 468 & 468 & $\mathrm{Mg}-\mathrm{O}$ \\
- & 524 & 526 & $\mathrm{Al}-\mathrm{O}$ \\
- & 1032 & 1036 & $\mathrm{Si}-\mathrm{O}$ \\
1271 & - & 1271 & $\mathrm{P}=\mathrm{O}$ \\
1725 & - & 1725 & $\mathrm{P}-\mathrm{OC}$ \\
2960 & - & 2960 & $-\mathrm{CH}_{2}$ \\
2859 & & 2859 & \\
\hline
\end{tabular}

the spectrum of ATMP-modified clay $\left(1036 \mathrm{~cm}^{-1}, 526 \mathrm{~cm}^{-1}\right.$ and $\left.468 \mathrm{~cm}^{-1}\right)$. The hydrocarbon chain of the ATMP gave bands at $2960 \mathrm{~cm}^{-1}$ and $2859 \mathrm{~cm}^{-1}$ and ATMP-modified clay also presented the same bands. The bands at $1271 \mathrm{~cm}^{-1}$ and $1725 \mathrm{~cm}^{-1}$ for ATMP and ATMP-modified clay were attributed respectively to the $\mathrm{P}=\mathrm{O}$ bond and to the $\mathrm{P}-\mathrm{OC}$ bond of the phosphonic group [33]. From the comparison of the three spectra (Fig. 1), it can be concluded that ATMP molecules were inserted in the clay backbone.

Fig. 2 shows X-ray diffraction patterns of the clay, of the ATMP-modified clay and of the ATMP-modified clay in the epoxy coating. The peak corresponding to the $d_{001}$ plane of the pristine clay appears at $2 \theta=7^{\circ}$ and for the ATMP-modified clay, it appears at $2 \theta=5.60^{\circ}$. The peak $d_{001}$ corresponds to the $d$ spacing of the lamellar structure of MMT. The comparison of the global spectra of clay and ATMP-modified clay (not presented in the paper) showed that only the peak for the low angle was modified indicating that the MMT crystal was not changed by the cation exchange reaction. $d$-spacing was calculated from Bragg's Law given in Eq. (1):

$\lambda=2 d \sin \theta$

where $\lambda$ is the wavelength of the $\mathrm{X}$-ray radiation, $\theta$ is the glancing angle and $d$ is the interplanar spacing of the clay layers.

From Fig. 2, the calculated $d$-spacing is $12.6 \AA$ and $15.8 \AA$ for the clay and for the ATMP-modified clay, respectively. The increase in $d_{001}$ spacing in the ATMP-modified clay compared to pure clay is due to the exchange of cations by ATMP which increased the gallery spacing. For the epoxy coating loaded with ATMP-modified clay there is a lack of any diffraction peak in the X-ray spectrum indicating that the interplanar spacing between the galleries is larger than $29.3 \AA$ (the lowest measured angle $(2 \theta)$ is of $3^{\circ}$ ) and thus, it can be concluded that a significant degree of intercalation dispersion has occurred in the epoxy matrix [34-37]. Small-angle X-ray scattering and

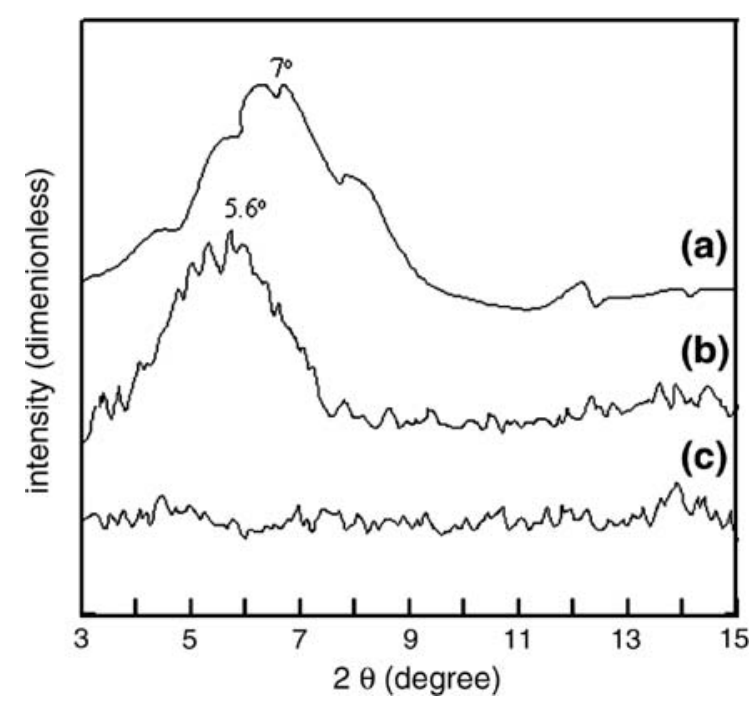

Fig. 2. X-ray diffraction spectra of (a) clay, (b) ATMP-modified clay and (c) ATMP-modified clay in the epoxy coating. 

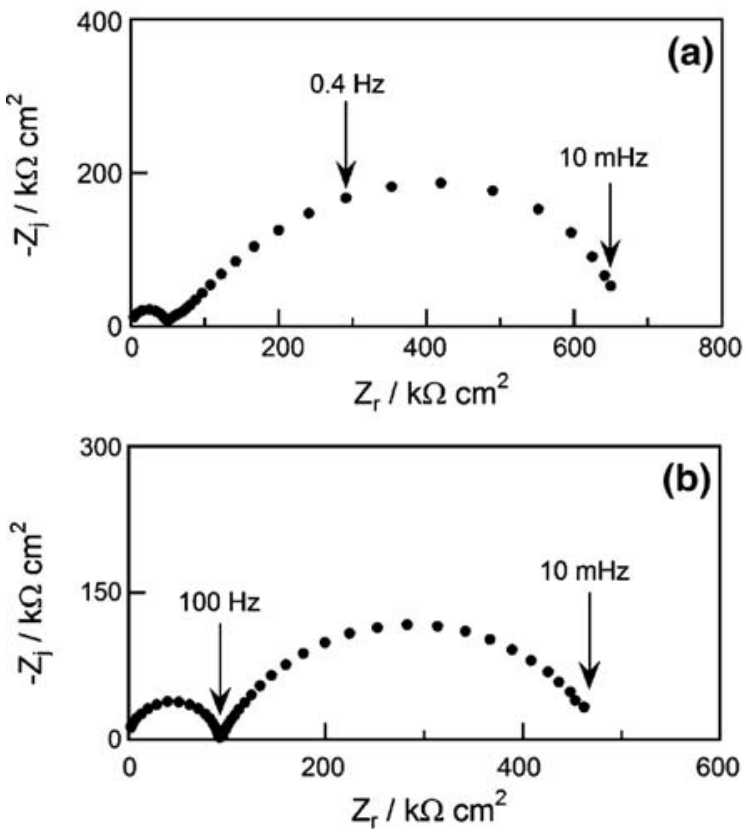

Fig. 3. Electrochemical impedance diagrams obtained for the carbon steel covered by the pure epoxy coating after (a) 7 days and (b) 56 days of exposure to the $0.5 \mathrm{M} \mathrm{NaCl}$ solution.

transmission electron microscopy would be necessary to reach the exact morphology of the silicate nanolayers in the epoxy coating.

\subsection{Conventional impedance}

Impedance diagrams were plotted at the corrosion potential to characterize the corrosion resistance of the carbon steel
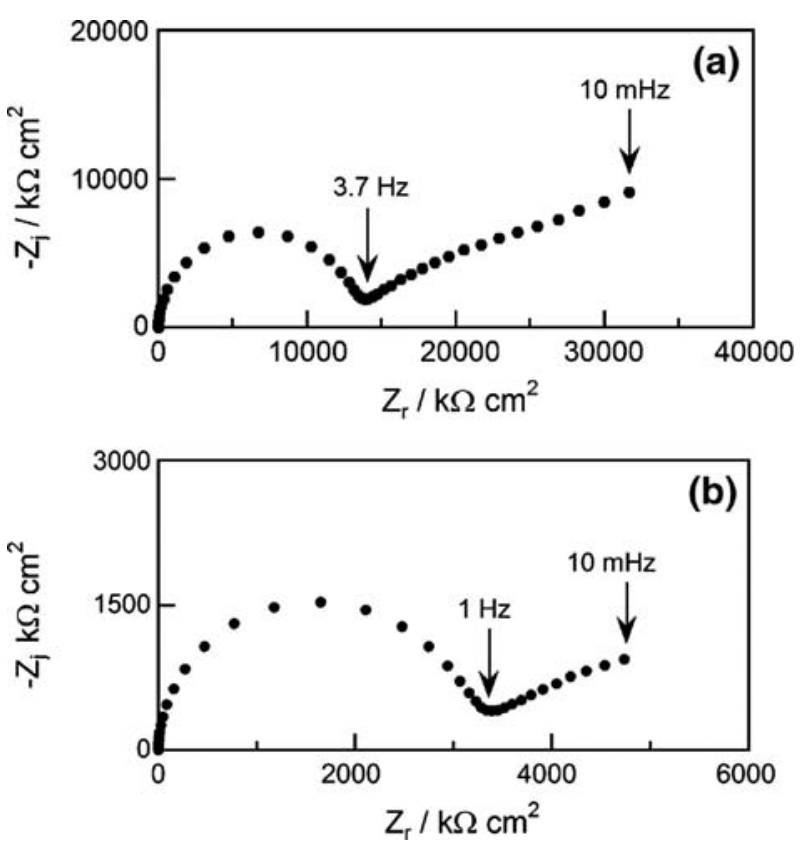

Fig. 4. Electrochemical impedance diagrams obtained for the carbon steel covered by the epoxy coating containing 2 wt.\% clay after (a) 7 days and (b) 56 days of exposure to the $0.5 \mathrm{M} \mathrm{NaCl}$ solution. covered by the pure epoxy coating, by the epoxy coating containing $2 \%$ clay and by the epoxy coating containing $2 \%$ ATMP-modified clay. As an example, the impedance diagrams plotted after 7 days and 56 days of exposure to the $0.5 \mathrm{M} \mathrm{NaCl}$ solution are presented in Figs. 3-5 for each of the three systems.

For the pure epoxy (Fig. 3), the diagrams are characterized by two well defined capacitive loops. For organic coatings, the usual interpretation of the impedance diagrams is the following: the high-frequency (HF) part is related to the organic coating while the low frequency (LF) part corresponds to the reactions occurring on the metal through defects and pores in the coating $[38,39]$.

For the epoxy coating containing 2 wt.\% of clay (Fig. 4), the diagrams are also characterized by two time constants. However, the second time constant is not well defined and in fact, a linear part appeared in the LF range, which suggests that diffusion processes occur through the coating [40]. The resistance values associated with the HF part are significantly higher than those obtained for pure epoxy. This is in agreement with the increase of the tortuous diffusion pathway of oxygen and water induced by the dispersion of silicate layers in the epoxy matrix [27,34].

For the epoxy coating containing 2\% ATMP-modified clay (Fig. 5), it can be noted that the diagrams are more depressed than those obtained for the other two systems. The impedance values are higher with ATMP-modified clay and in addition, the values remained high when the exposure time increased. Thus, it can be concluded that the presence of ATMP molecules in the MMT backbone is responsible of the observed behaviour.

As in previous works $[41,42]$, the values of the resistance associated to the HF loop $\left(R_{\mathrm{f}}\right)$, extracted from the impedance diagrams, was used to follow the degradation of the different
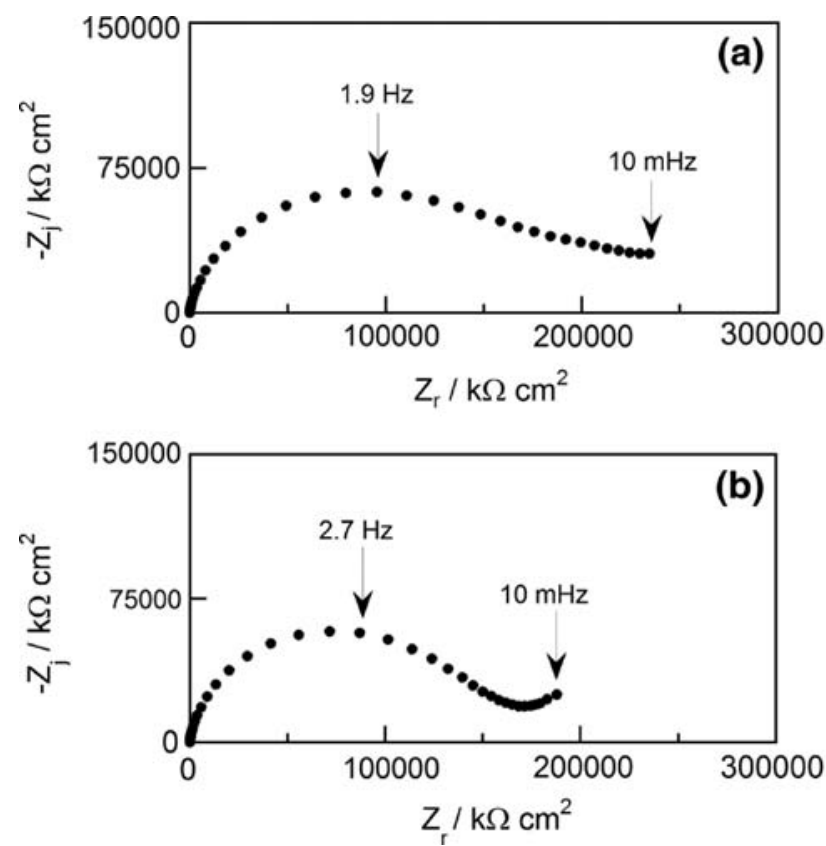

Fig. 5. Electrochemical impedance diagrams obtained for the carbon steel covered by the epoxy coating containing $2 \mathrm{wt} \%$ ATMP-modified clay after (a) 7 days and (b) 56 days of exposure to the $0.5 \mathrm{M} \mathrm{NaCl}$ solution. 


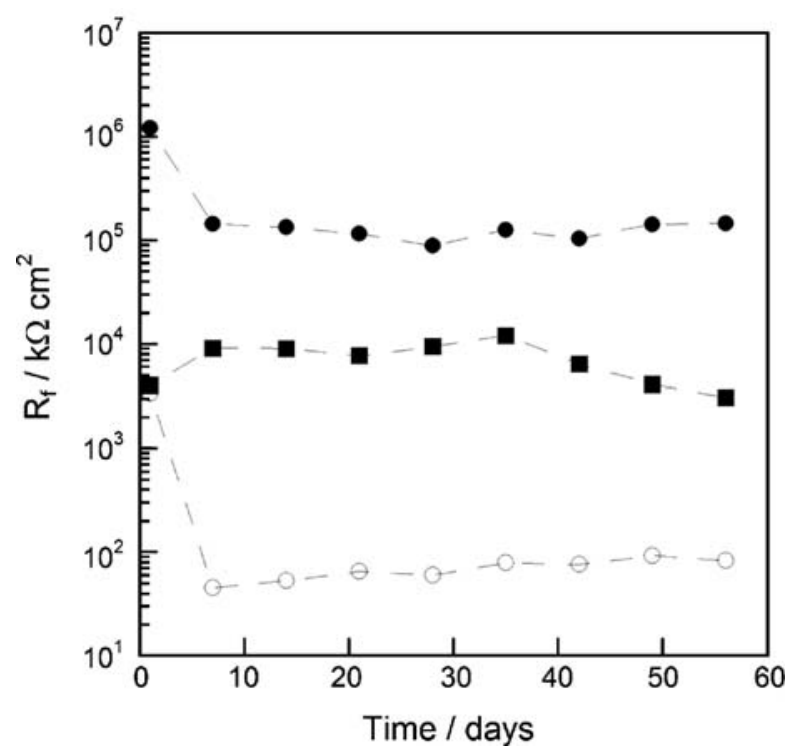

Fig. 6. $R_{\mathrm{f}}$ versus immersion time in the $0.5 \mathrm{M} \mathrm{NaCl}$ solution for the carbon steel covered by $(\bigcirc)$ pure epoxy, $(\square)$ epoxy containing 2 wt.\% clay and (O) epoxy containing 2 wt.\% ATMP-modified clay.

systems with exposure time in the aggressive solution. $R_{\mathrm{f}}$ was obtained by a fitting procedure. The impedance $R_{\mathrm{f}}$ is associated with ionic transport through the coating and thus, gives information on the barrier properties of the coating. Fig. 6 reports the variation of $R_{\mathrm{f}}$ as a function of exposure time in the aggressive solution.

For the pure epoxy coating, $R_{\mathrm{f}}$ decreased rapidly during the first 7 days of immersion, then, it remained stable with immersion time at a low value (around $50 \mathrm{k} \Omega \mathrm{cm}^{2}$ ). This result indicates a rapid loss of the barrier properties of the film. The fall of $R_{\mathrm{f}}$ during the first few days of exposure was attributed to the penetration of the electrolyte through the coating. It is clear that the introduction of the clay particles in the epoxy coating led to a significant improvement of the barrier properties. Nevertheless, the comparison of $R_{\mathrm{f}}$ between the coating containing natural clay and the coating containing ATMP-modified clay revealed that the presence of ATMP improved the barrier properties of the coating. For the epoxy coating containing ATMP-modified clay, the film resistance decreased during the first 7 days of immersion, and then kept a high constant value compared to pure epoxy coating (around 1000 times higher) at longer exposure times. The high value of $R_{\mathrm{f}}$ can be explained by a good dispersibility of the organically modified clay in the resin.

The LF part of the diagrams is not well defined (see for example, Figs. $4 \mathrm{a}$ or $5 \mathrm{~b}$ ) and consequently the parameters associated to the corrosion process (charge transfer resistance and double layer capacitance) cannot be readily extracted. The low frequency points are extremely tedious to obtain and often no longer reliable. A lower limit of $10 \mathrm{mHz}$ was set for all the experiments. Nevertheless, from Figs. 3-5, it appears that the impedance values in the low frequency range allow the following qualitative ranking: $Z_{\text {epoxy coating }}<Z_{\text {epoxy coating }+2 \% \text { clay }}<$ $Z_{\text {epoxy coating }+ \text { ATMP-modified clay }}$

\subsection{Localized electrochemical impedance mapping}

Figs. 7 and 8 present LEI maps obtained after two times of exposure to the $0.5 \mathrm{M} \mathrm{NaCl}$ solution for the pure epoxy coating and for the epoxy containing 2\% ATMP-modified clay, respectively. For both systems, on the edge of the scratch, admittance increases (impedance decreases) when the exposure time to the aggressive solution increases. It can be assumed that the high admittance values (low impedance values) correspond to a loss of adherence of the coating indicating delamination [30]. After 12 days of immersion, the measured delaminated area (evaluated from 2D plots) was approximately the same for the two systems. It is noteworthy that in the scratch, the behaviour of the two systems was different. For the pure epoxy coating, admittance remained high. After the test, visual observation revealed the presence of brown, rusty and poorly adherent corrosion products. For the epoxy coating containing 2\% ATMP-modified clay, admittance was always lower than the admittance measured for pure epoxy. This result indicates the inhibitive action of ATMP at
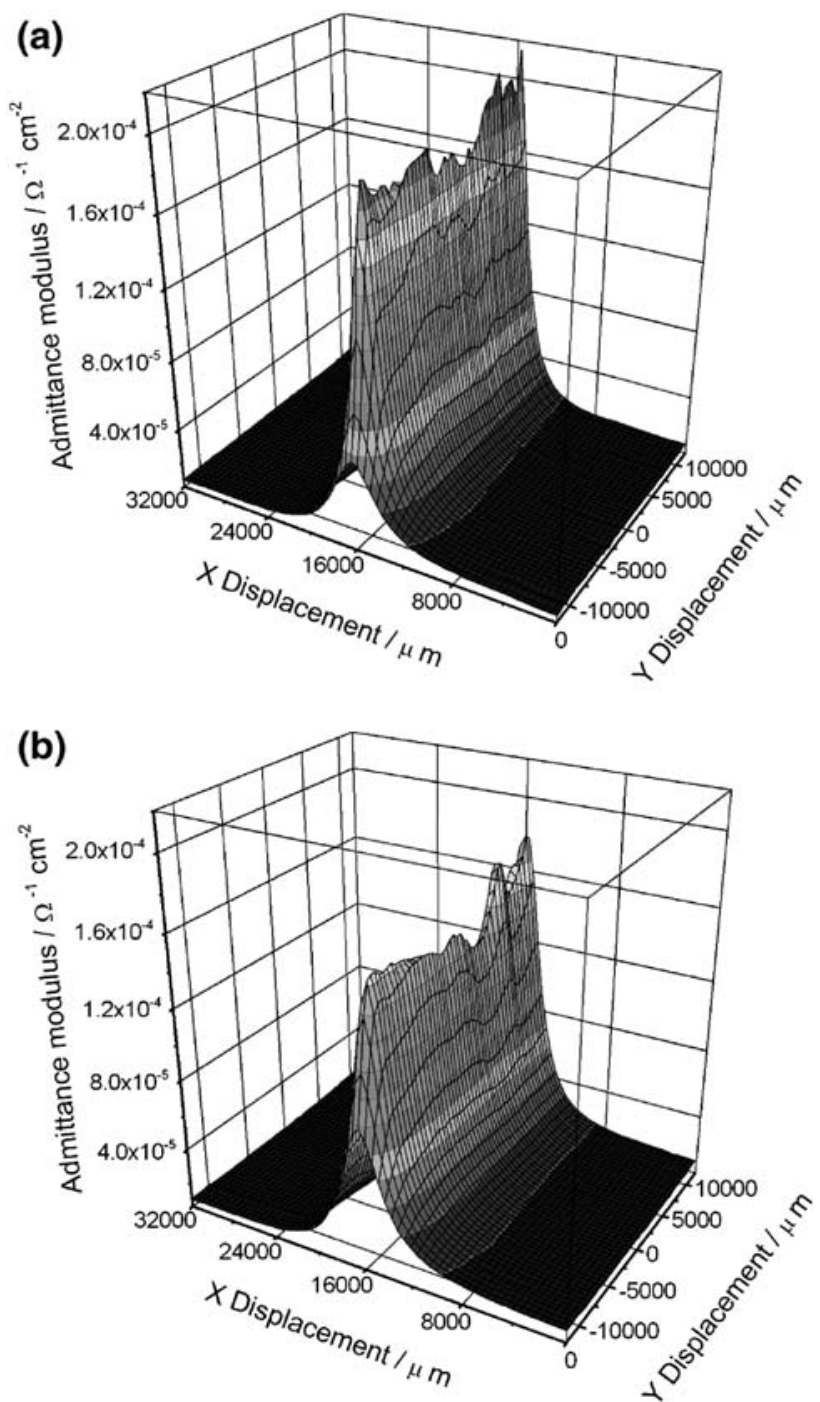

Fig. 7. LEIM carried out at $5 \mathrm{kHz}$ for the pure epoxy resin around the scratched area (a) after 5 days and (b) after 12 days of immersion in the aggressive $\mathrm{NaCl}$ solution. 


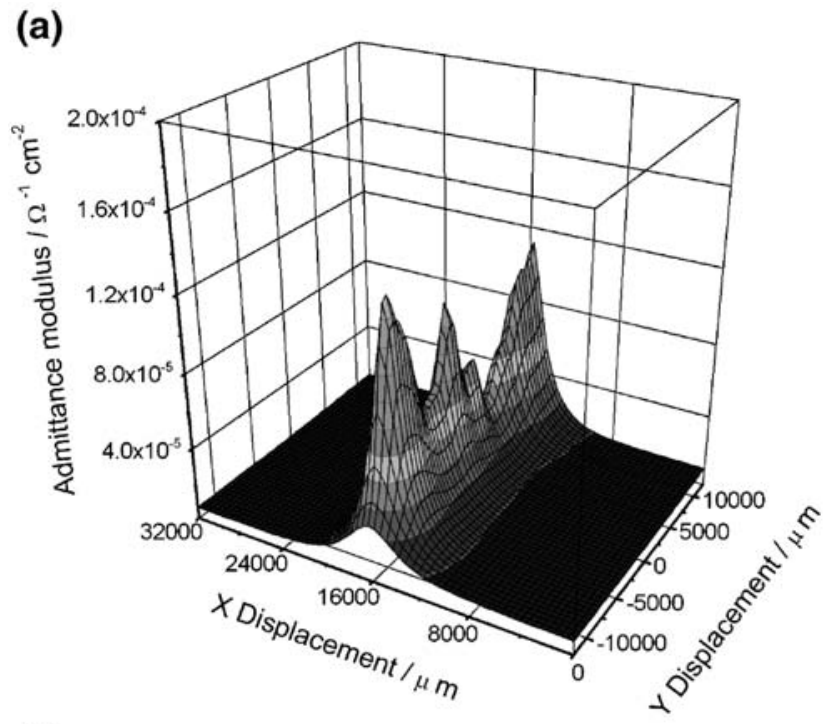

(b)

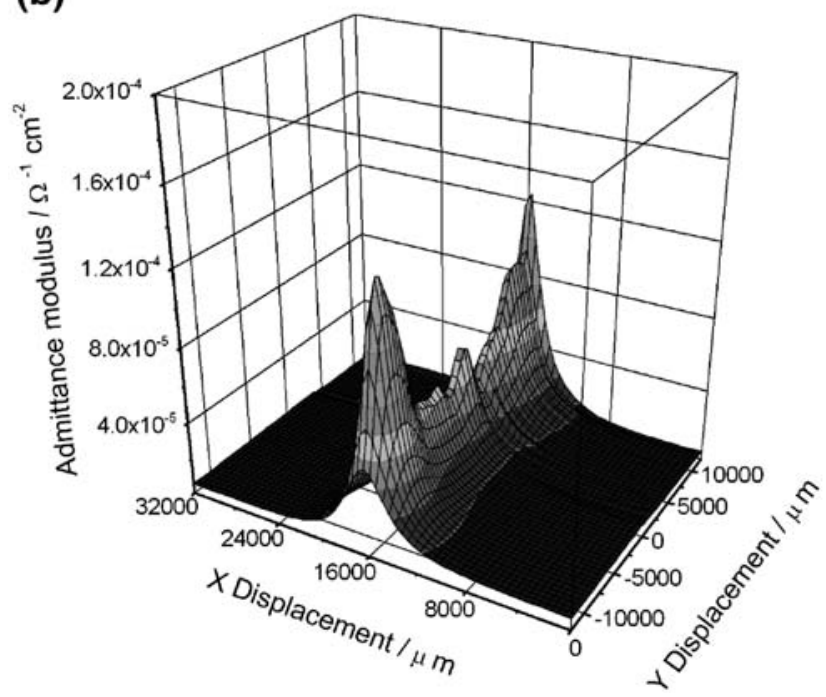

Fig. 8. LEIM carried out at $5 \mathrm{kHz}$ for the epoxy resin containing 2 wt.\% ATMPmodified clay around the scratched area (a) after 5 days and (b) after 12 days of immersion in the aggressive $\mathrm{NaCl}$ solution.

the carbon steel surface as well as in the scratch area. Here, after 12 days of exposure, the visual observation revealed the presence of black, adherent corrosion products.

From local analysis, it can be concluded that the corrosion protection afforded by ATMP-modified clay is significant. Nevertheless, the adhesion of the coating is not modified by comparison with pure epoxy. Good coating adherence will be required to develop an efficient protective primer.

\subsection{Interface characterization}

To characterize the action of ATMP-modified clay at the carbon steel surface, the following experiment was performed: the carbon steel electrode was dipped into an aqueous solution containing ATMP-modified clay ( $0.25 \mathrm{wt} . \%)$ for $2 \mathrm{~h}$. Then, the carbon steel surface was observed by SEM and compared to an image of ATMP-modified clay alone (Fig. 9). The two photographs show the same morphology. In Fig. 9a, the lamellar structure of the clay is clearly visible. In Fig. 9b, it can be seen that a relatively thick and porous layer of ATMP-modified clay covered the carbon steel surface. This shows that in aqueous solution, the ATMP-modified clay reaches the electrode surface and deposits. It is noteworthy that when the carbon steel electrode was dipped into an aqueous solution containing clay $(0.25$ wt.\%), the carbon steel surface was bright, without any deposit.

In a second step, a cross-section of the carbon steel covered by the epoxy coating containing ATMP-modified clay was made to analyse the distribution of the ATMP-modified clay in the coating. A SEM image and element distribution in the epoxy coating are shown in Figs. 10 and 11, respectively. In Fig. 10, the organic coating appears homogeneous. In Fig. 11, the presence of ATMPmodified clay should give rise to silica, aluminium and magnesium peaks. However, in the coating, only carbon and oxygen are detected (Fig. 11a). The clay is not detected due both to the small size of the sheets (about $10 \AA$ ) and its low content (2\%). Conversely, peaks of carbon, oxygen, iron, silica, aluminium and magnesium are observed at the steel/coating interface (Fig. 11b). Thus, it can be assumed that part of the ATMP-modified clay accumulates at the interface. This can be attributed to migration of the treated clay to

(a)

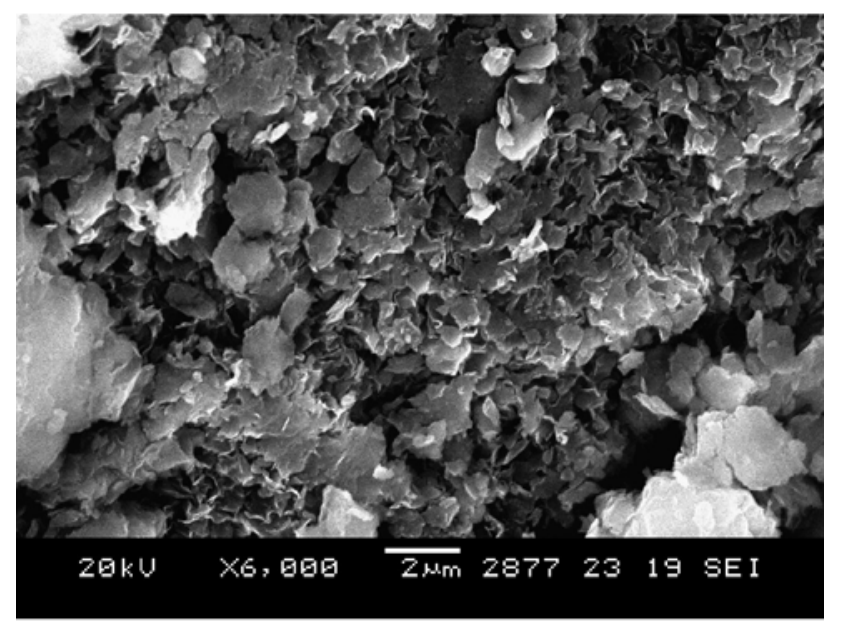

(b)

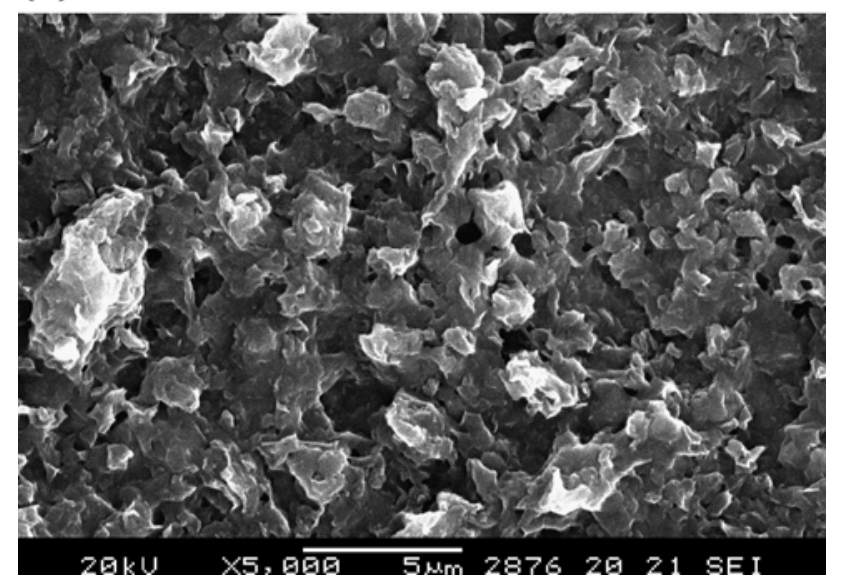

Fig. 9. SEM pictures of (a) ATMP-modified clay and (b) a carbon steel surface after $2 \mathrm{~h}$ of immersion in the ATMP-modified clay solution. 


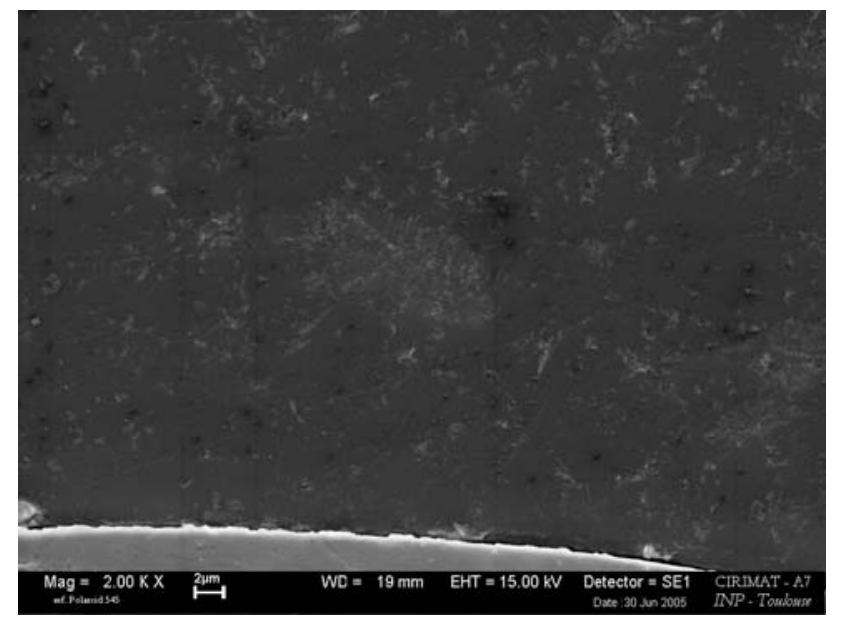

Fig. 10. SEM image of a cross-section of the epoxy coating/carbon steel interface. the carbon steel surface through the epoxy coating, probably during the application of the resin, before the cross-linking step. This hypothesis is supported by the results obtained in the aqueous solution (Fig. 9).

According to Gonzalez et al. [28,29], ATMP reacts with $\mathrm{Fe}^{2+}$ ion to form a complex at the steel surface affording protection for the carbon steel. From both electrochemical impedance measurements and surface analysis, it can be concluded that the ATMP-modified clay plays a role on the barrier effect and also acts as a corrosion inhibitor at the carbon steel/coating interface.

\section{Conclusion}

ATMP-modified clay was prepared by cation exchange reaction. The infrared analysis shows the insertion of ATMP in the backbone of the clay. From the impedance measurements, it was found that the presence of ATMP-modified clay significantly enhanced the protective properties of the epoxy coating. Crosssection analysis of carbon steel covered by an epoxy coating
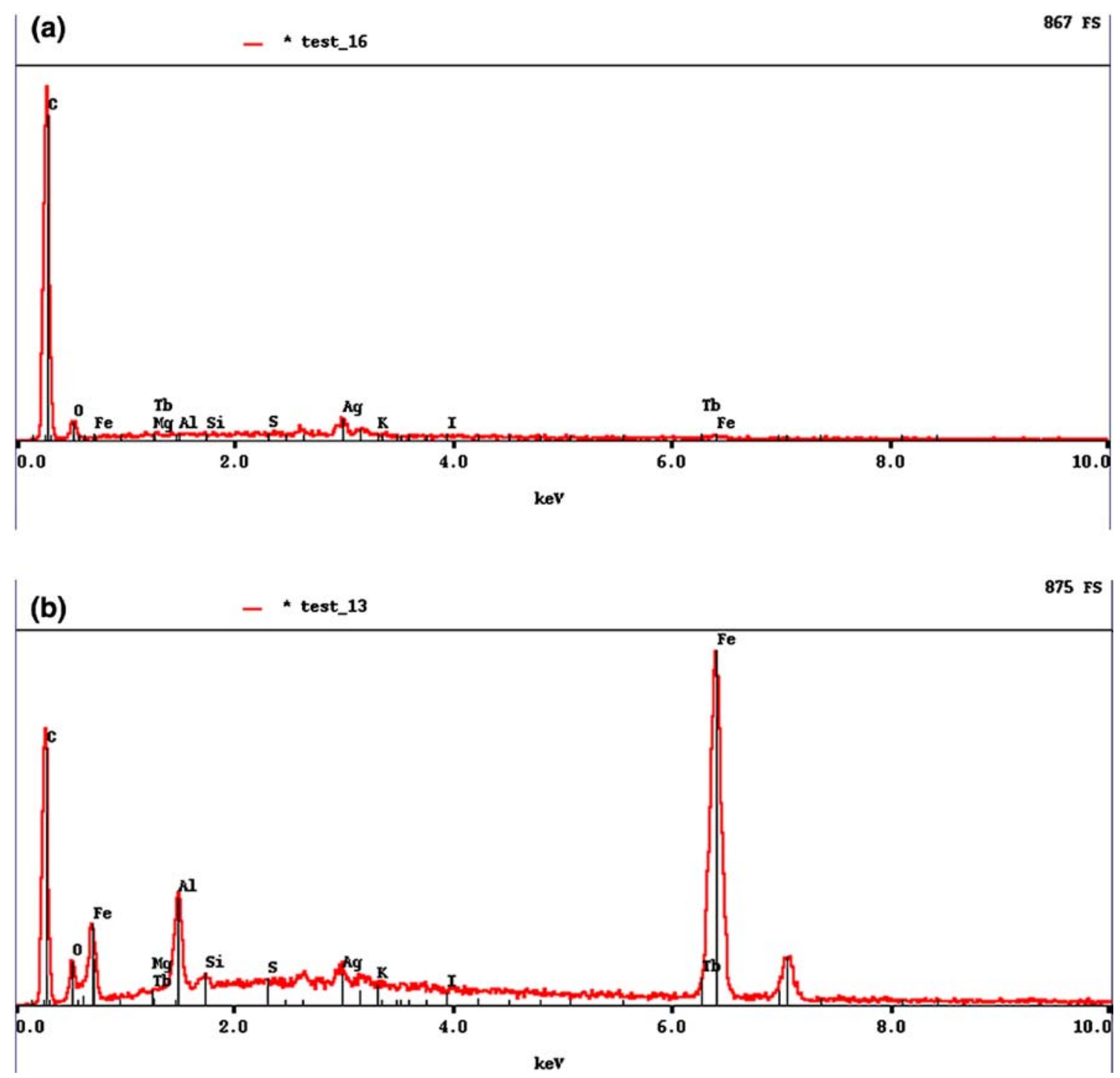

Fig. 11. EDS spectra of (a) the bulk epoxy film and (b) the epoxy film/carbon steel interface. 
containing ATMP-modified clay shows the presence of ATMPmodified clay at the steel/epoxy coating interface. The corrosion protection performance of the epoxy coating in the presence of ATMP-modified clay was explained by both the barrier properties due to the lamellar structure of the clay and the corrosion inhibition at the carbon steel surface due to the presence of phosphonic functions on the organic molecule.

The good performance of the coating containing clay modified by organic compounds shows the feasibility of developing new formulations without toxic inhibitors.

\section{Acknowledgments}

This work was carried out with financial support from AUF and from CNRS (France). The authors gratefully acknowledge Dr. Djar Oquab for his most valuable assistance in the area of SEM-EDS.

\section{References}

[1] J.W. Gilman, Appl. Clay Sci. 15 (1999) 31.

[2] K.A. Carrado, Appl. Clay Sci. 17 (2000) 1.

[3] R. Wagener, T.J.G. Reisinger, Polymer 44 (2003) 7513.

[4] G. Gorrasi, M. Tortora, V. Vittoria, E. Pollet, B. Lepoittevin, M. Alexandre, P. Dubois, Polymer 44 (2003) 2271.

[5] M. Arroyo, M.A. Lopez-Manchado, B. Herrero, Polymer 44 (2003) 2447.

[6] J. Park, S.C. Jana, Polymer 45 (2004) 7673.

[7] X. Cao, L.J. Lee, T. Widya, C. Macosko, Polymer 46 (2005) 775.

[8] Y. Someya, M. Shibata, Polymer 46 (2005) 4891.

[9] H. Liu, W. Zhang, S. Zheng, Polymer 46 (2005) 157.

[10] C. Ding, D. Jia, H. He, B. Guo, H. Hong, Polym. Test. 24 (2005) 94.

[11] R.K. Shah, D.R. Paul, Polymer 47 (2006) 4075.

[12] M.S. Hedenqvist, A. Backman, M. Gällstedt, R.H. Boyd, U.W. Gedde, Compos. Sci. Technol. 66 (2006) 2350.

[13] Y. Zhou, F. Pervin, M.A. Biswas, V.K. Rangari, S. Jeelani, Mater. Lett. 60 (2006) 869.

[14] I. Hackman, L. Hollaway, Compos., Part A Appl. Sci. Manuf. 37 (2006) 1161.

[15] Y. Xu, W.J. Brittain, R.A. Vaia, G. Price, Polymer 47 (2006) 4564
[16] T. Peprnicek, J. Duchet, L. Kovarova, J. Malac, J.F. Gerard, J. Simonik, Polym. Degrad. Stab. 91 (2006) 1855.

[17] C. Chen, M. Khobaib, D. Curliss, Prog. Org. Coat. 47 (2003) 376.

[18] W.D. Kingery, H.K. Bowen, D.R. Uhlmann, Introduction To Ceramics, 2nd ed., John Wiley \& Sons, New York, 1976, p. 77.

[19] J.Y. Lee, H.K. Lee, Mater. Chem. Phys. 85 (2004) 410-415.

[20] J. Morawiec, A. Pawlak, M. Slouf, A. Galeski, E. Piorkowska, N. Krasnikowa, Eur. Polym. J. 41 (2005) 1115.

[21] A. Gu, G. Liang, Polym. Degrad. Stab. 80 (2003) 383.

[22] P. Meneghetti, S. Qutubuddin, Thermochim. Acta 442 (2006) 74.

[23] T. Sugama, Mater. Lett. 60 (2006) 2700.

[24] J.-M. Yeh, C.-L. Chen, Y.-C. Chen, C.-Y. Ma, K.-R. Lee, Y. Wei, S. Li, Polymer 43 (2002) 2729.

[25] J.-M. Yeh, S.-J. Liou, C.-Y. Lin, C.-Y. Cheng, Y.-W. Chang, K.-R. Lee, Chem. Mater. 14 (2002) 154.

[26] Y.-H. Yu, J.-M. Yeh, S.-J. Liou, Y.-P. Chang, Acta Mater. 52 (2004) 475.

[27] J.-M. Yeh, H.-Y. Huang, C.-L. Chen, W.-F. Su, Y.-H. Yu, Surf. Coat. Technol. 200 (2006) 2753.

[28] Y. Gonzalez, M.C. Lafont, N. Pébère, G. Chatainier, J. Roy, T. Bouissou, Corros. Sci. 37 (1995) 1823.

[29] Y. Gonzalez, M.C. Lafont, N. Pébère, F. Moran, J. Appl. Electrochem. 26 (1996) 1259.

[30] J.B. Jorcin, E. Aragon, C. Merlatti, N. Pébère, Corros. Sci. 48 (2006) 1779.

[31] G. Baril, C. Blanc, M. Keddam, N. Pébère, J. Electrochem. Soc. 150 (2003) B488.

[32] J. Madejová, Vibr. Spectrosc. 31 (2003) 1.

[33] R.O. Carter III, C.A. Gierczak, R.A. Dickie, Appl. Spectrosc. 40 (1986) 649.

[34] P.C. LeBaron, Z. Wang, T.J. Pinnavaia, Appl. Clay Sci. 15 (1999) 11.

[35] D. Ratna, O. Becker, R. Krishnamurthy, G.P. Simon, R.J. Varley, Polymer 44 (2003) 7449.

[36] C. Zhao, H. Qin, F. Gong, M. Feng, S. Zhang, M. Yang, Polym. Degrad. Stab. 87 (2005) 183.

[37] G.W. Beall, M. Goss, Appl. Clay Sci. 27 (2004) 179.

[38] L. Beaunier, I. Epelboin, J.C. Lestrade, H. Takenouti, Surf. Technol. 4 (1976) 237.

[39] N. Pébère, T. Picaud, M. Duprat, F. Dabosi, Corros. Sci. 29 (1989) 1073.

[40] L. Jianguo, G. Gaoping, Y. Chuanwei, Electrochim. Acta 50 (2005) 3320.

[41] C. Le Pen, C. Lacabanne, N. Pébère, Prog. Org. Coat. 46 (2003) 77.

[42] A.T. Trinh, N. Pébère, T.X.H. To, Y. Hervaud, B. Boutevin, Prog. Org. Coat. 49 (2004) 130 